\title{
Effect of formation water and hydrochloric acid on the physical and chemical properties of polymer materials of high pressure pipelines used for transportation of crude oil
}

\author{
Dmitrii Aiduganov ${ }^{1, *}$, Dinar Balkaev², Mikhail Varfolomeev ${ }^{2}$, Dmitrii Emelianov $^{2}$ \\ ${ }^{1}$ Engineering Production Center (EPC), 423233, Bugulma, Russia \\ ${ }^{2}$ Kazan Federal University, 420008, Kazan, Russia
}

\begin{abstract}
The purpose of the work is to conduct a comparative analysis of the stability of two types of polymer coatings to the effects of formation water and hydrochloric acid based on the analysis of mechanical properties, thermal stability and surface morphology. To accomplish the task, modern physicalchemical methods were used: differential scanning calorimetry, microscopy, an electromechanical universal testing machine, a dilatometer. Simulation of the effect of water at elevated temperatures and pressures on the polymer coating samples was carried out in an autoclave-reactor, the study of the effect of acid was carried out in a glass beaker. On the basis of the work carried out, results were obtained that show similarities and differences in the behavior of the polymer samples studied. The change of the dynamic modulus of elasticity and the coefficient of linear thermal expansion with increasing temperature is investigated. In general, it has been shown that PE-RT polymer has better characteristics than PE polymer. However, both of them are stable to the exposure of formation water and hydrochloric acid and can protect corrosion of high pressure pipes connections.
\end{abstract}

\section{Introduction}

Transportation of injected fluids, recovered products, and formation fluids is an important part of exploitation processes. The pipelines used for these processes are responsible for the durability and stability of transportation processes. Nowadays, in modern pipelines polymeric materials are increasingly used [1]. They allow to solve a number of operational problems, including ensuring the strength of the connection of pipes between each other. The most common polymers used today in the oil industry for pipelines are polymers based on polyethylene. This polymer has the necessary strength and flexibility for the manufacture of pipeline connections. However, it has certain limitations on thermal stability; therefore, new grades of polyethylene are being developed that solve this problem [3]. In addition to temperature, the components of the transported fluid may affect the properties of the polymer during operation. These include oil, chemicals, formation water and acids. The reservoir water contains a large amount of salts that can adsorb on the surface of the polymer coating and affect its properties [4]. In turn, acids, among which hydrochloric acid is most often used, can also affect the polymer coating. In this regard, in order to ensure the stability of the polymer coating during transportation of the extracted or injected products, it is necessary to study the effect of formation water and acid on its physicochemical properties. This was the goal of our work. We studied the effect of formation water and hydrochloric acid under long-term exposure at elevated temperature to samples of two polymeric materials. Two samples of polyethylene of different molecular weight were selected as polymeric materials. After exposure to formation water and hydrochloric acid, the mechanical properties of polymers, their thermal stability and surface morphology were studied.

Based on these studies, conclusions were made about the applicability of polymeric materials based on polyethylene when transporting liquids containing formation water and hydrochloric acid.

\section{Materials}

The objects of study are samples of polymer coatings based on two types of polyethylene PE and PE-RT before and after exposure.

\section{Experimental part}

Experiments on the effects of formation water and oil on samples of polymer coating of high-pressure pipes were carried out on a batch stainless steel reactor $(4575 / 76$ HP/HT Reactor, Parr Instruments).

In the preparation of polymeric material for testing on a laboratory pneumatic press NoselabATS, samples were cut out according to standard forms.

During the first two experiments, samples of polymer coatings were placed in an amount of 5 pieces. After that, the reservoir water was injected into the reactor so

\footnotetext{
${ }^{*}$ Corresponding author: technical@ipc-bugulma.ru
} 
that all samples were completely immersed in the liquid. Next, inert gas was supplied to the system to create pressure. The experiments were carried out at $25 \mathrm{MPa}$ and at a temperature of $40^{\circ} \mathrm{C}$. The time of each experiment was 240 hours.

The effect of acid on the studied polymer coatings was carried out in a glass beaker. The acid used was a $10 \%$ aqueous solution of hydrochloric acid. The experiments were carried out at a temperature of $50^{\circ} \mathrm{C}$ for 24 hours.

\section{Mechanical Testing}

The determination of tensile yield strength and relative elongation at yield strength was carried out in accordance with the standard ASTM D 638 on an Instron 5882 universal testing machine with a specialized tool for tensile, longitudinal strain measurements were carried out using an extensometer.

\section{Tensile test results:}

According to the measurement results, graphs of the stress versus strain of the samples were plotted, shown in the figures 1,2 .

\section{Discussion of tensile test results:}

Tests have shown good convergence of the results and the normal nature of the plastic deformation of the samples. According to the results of tensile tests on samples of polymer pipes without exposure and after various methods of exposure including formation water and acid, the following is observed: physical-mechanical characteristics at stretching the samples of PE and PE RT pipes. These two aggressive media (formation water,
$10 \%$ aqueous $\mathrm{HCl}$ solution) affect the physical and mechanical characteristics slightly (deterioration from $1 \%$ to $11 \%$ ).

Measurement of linear thermal expansion coefficients of a polymer coating

The DIL 802 dilatometer provides differential measurement of the difference between the sample and the reference sample, the design subtracts the effect of the expansion of the measuring system when measuring the sample. Measurements are carried out with an integrated LVDT sensor connected to the sample using a pusher that moves with the expansion of the sample being measured. There is also a second follower in contact with the reference sample. The tube moves in response to thermal expansion of the system and eliminates the need for corrective and calibration tests. Each series of tests was carried out on 3 samples samples in the form of a bar with a size of $25 \times 4 \times 4 \mathrm{~mm}$ were used for testing. The linear thermal expansion coefficient (CTE) was determined on a horizontal DIL 802 dilatometer (TA Instruments). The experiments were carried in the temperature range from 30 to $100^{\circ} \mathrm{C}$ with heating rate $3 \mathrm{~K} / \mathrm{min}$.

\section{Measurement results of CTE:}

According to the measurement results, the graphs of the dependence of CTE on temperature in the measured range of 30-100 0C, shown in the figures 3, 4 .
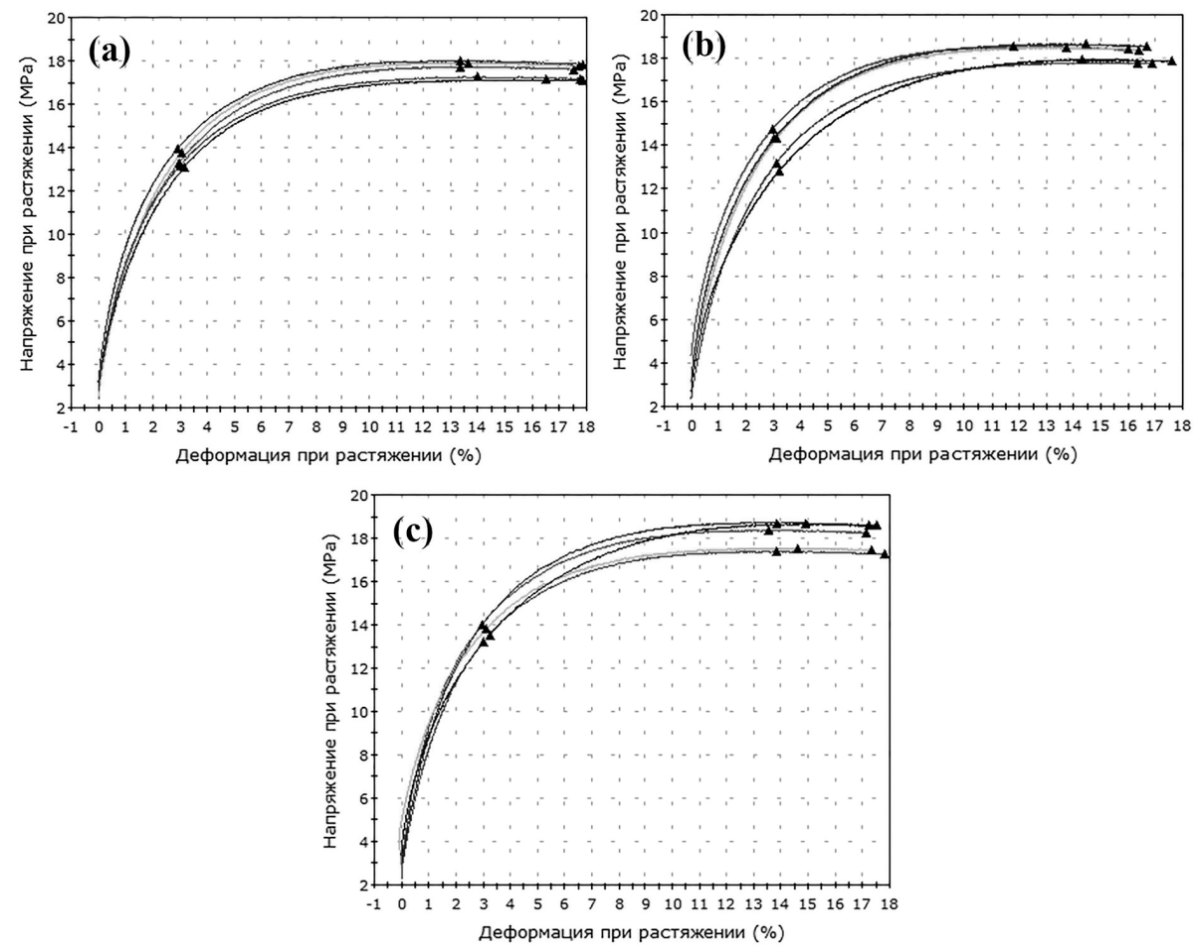

Fig. 1. Tensile stress-strain curves of PE pipe: (a) no impact, (b) after exposure to formation water for 240 hours at $25 \mathrm{MPa}$ and $40^{\circ} \mathrm{C}$, (c) after exposure to $10 \%$ aqueous $\mathrm{HCl}$ solution at $50^{\circ} \mathrm{C}$ for 24 hours. 

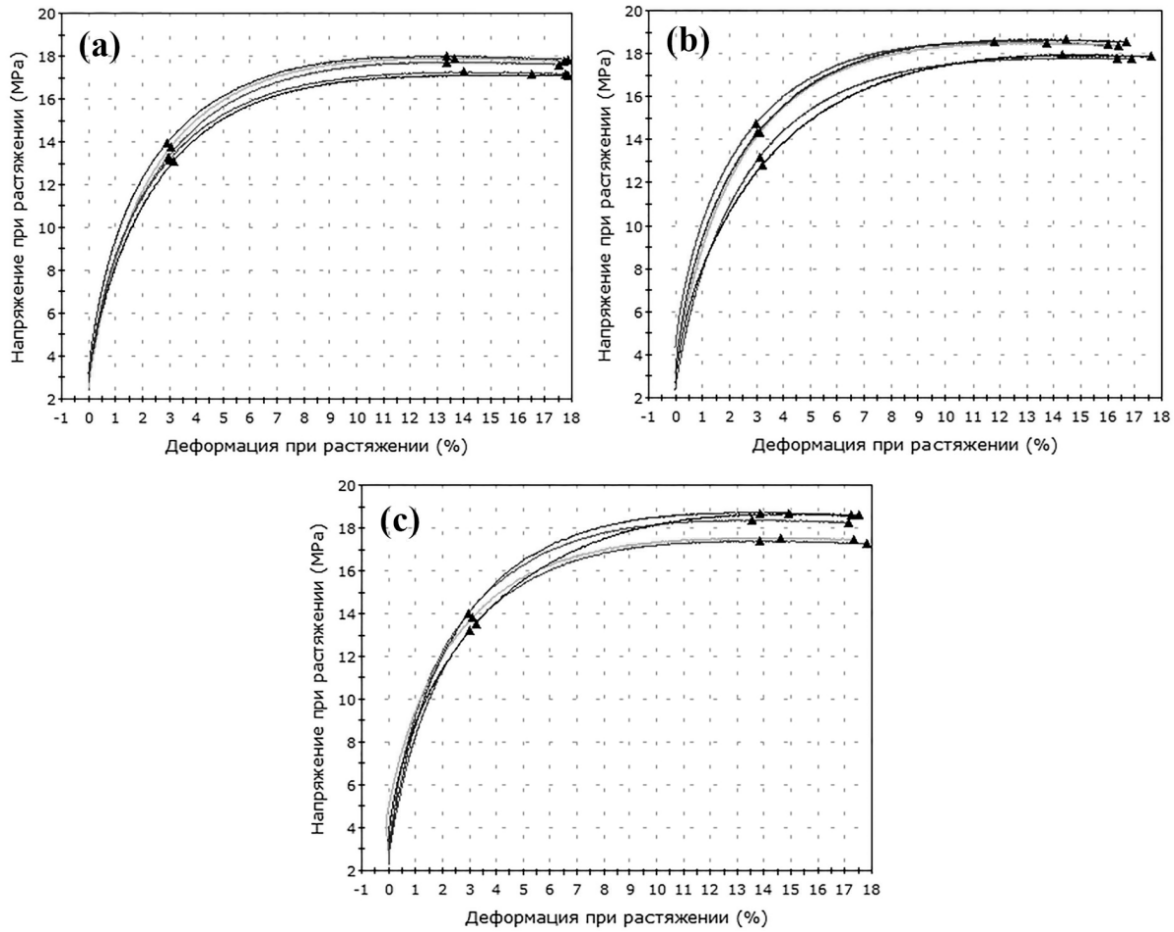

Fig. 2. Tensile stress-strain curves of PE-RT pipe: (a) no impact, (b) after exposure to formation water for 240 hours at $25 \mathrm{MPa}$ and $40^{\circ} \mathrm{C}$, (c) after exposure to $10 \%$ aqueous $\mathrm{HCl}$ solution at $50^{\circ} \mathrm{C}$ for 24 hours.

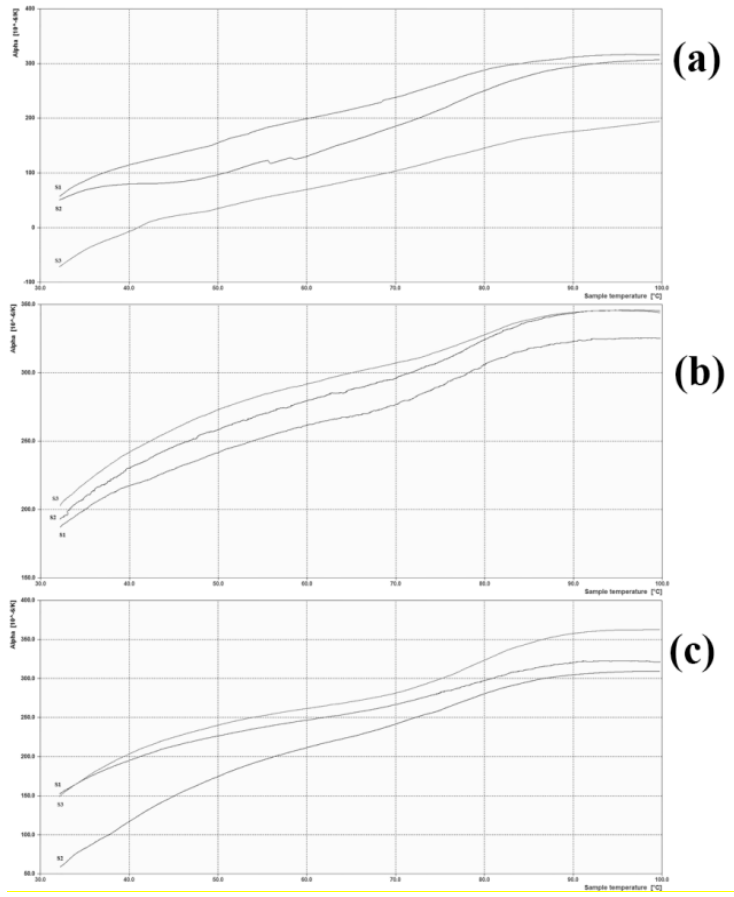

Fig. 3. Graphs of linear thermal expansion coefficient from temperature for PE pipe: (a) no impact, (b) after exposure to formation water for 240 hours at $25 \mathrm{MPa}$ and $40^{\circ} \mathrm{C}$, (c) after exposure to $10 \%$ aqueous $\mathrm{HCl}$ solution at $50^{\circ} \mathrm{C}$ for 24 hours.

Discussion of linear thermal expansion coefficient measurement results:

According to the results of measurements of the coefficient of linear thermal expansion in samples of polymer pipes without exposure and after exposure to by

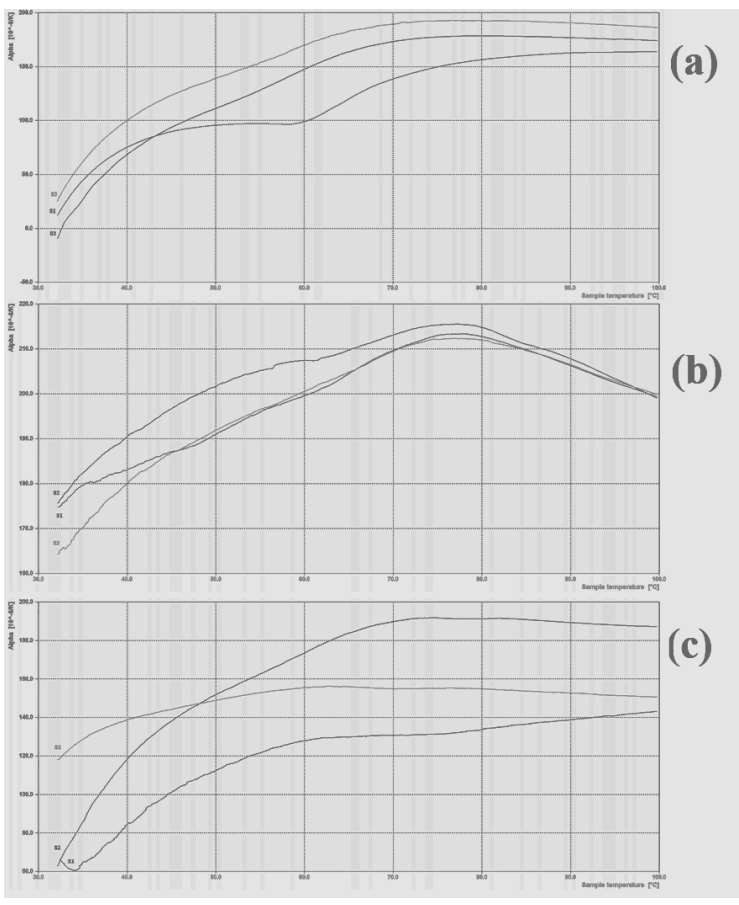

Fig. 4. Graphs of linear thermal expansion coefficient from temperature for PE-RT pipe: (a) no impact, (b) after exposure to formation water for 240 hours at $25 \mathrm{MPa}$ and $40^{\circ} \mathrm{C}$, (c) after exposure to $10 \%$ aqueous $\mathrm{HCl}$ solution at $50^{\circ} \mathrm{C}$ for 24 hours.

formation water and acid, the following is observed: CTE values in the temperature range from 30 to $100{ }^{\circ} \mathrm{C}$ for sample PE - 300* 10-6 (K-1), for sample PE - RT $192 * 10-6(\mathrm{~K}-1)$. After exposure to various corrosive media (formation water, $10 \%$ aqueous $\mathrm{HCl}$ solution) the CTE values for the PE sample increase by $16.7-17.6 \%$ and for PE-RT these changes are not significant. 
Conducting experiments on the study of polymers before and after exposure by the method of differential scanning calorimetry

The experiments were performed on a DSC 214 Polyma differential scanning calorimeter (Netzsch $\mathrm{GmbH}$ ). The experiments were carried out in a dynamic nitrogen environment. Cyclic heating at atmospheric conditions (1 atm) in aluminum crucibles with a punctured lid up to $180{ }^{\circ} \mathrm{C}$ at a rate of $10{ }^{\circ} \mathrm{C} / \mathrm{min}$ in nitrogen atmosphere and subsequent cooling to $80{ }^{\circ} \mathrm{C}$ at a rate of $10{ }^{\circ} \mathrm{C} / \mathrm{min}$ followed by an isotherm of 10 minutes - a threefold cycle, the flow rate of the purge gas $30 \mathrm{ml} / \mathrm{min}$ (oven protection nitrogen flow $45 \mathrm{ml} / \mathrm{min}$ ). The mass of the samples ranged from 10 to $11 \mathrm{mg}$.

Discussion of DSC test results for PE-RT polymer:

It is shown that the parameters of the PE-RT polymer melting process (Figs. 5,6), namely, the temperature and the thermal effect, practically coincide with the similar parameters for the PE polymer. The process also proceeds in one stage without decomposition of the substance. It was found that exposure with formation water and hydrochloric acid solution do not have a noticeable effect on the melting parameters of the polymer.

Study of the surface morphology of the polymer material (cracking, the appearance of defects)

The surface morphology of the polymer material was measured using a Merlin (Carl Zeiss) high-emission scanning electron microscope (Fig. 7). Samples were prepared for the experiments. To do this, pre-fixed to the holder samples of the polymer coating were placed in the chamber of the Quorum Q 150T ES vacuum unit. The conductive layer was deposited using the method of cathode sputtering of an $\mathrm{Au} / \mathrm{Pd}$ alloy in a ratio of 80/20. The thickness of the applied layer is $15 \mathrm{~nm}$. According to obtained results it can be concluded that formation water and acid do not affect significantly on the surface of polymers. Polymer PE-RT has a smoother surface than PE.

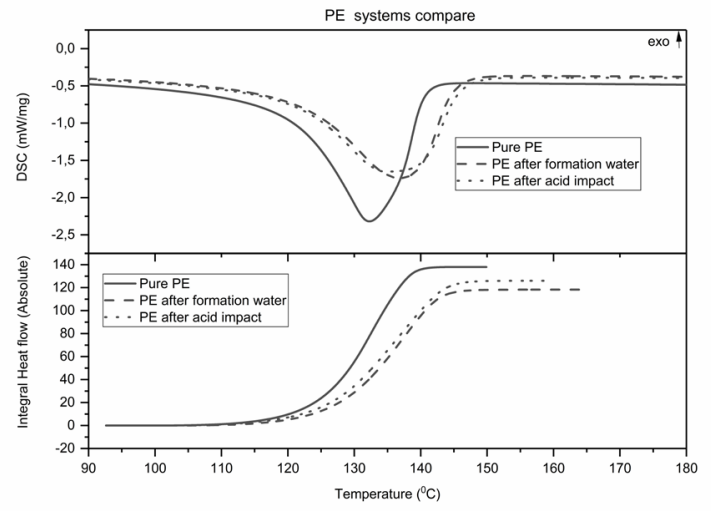

Fig. 5. DSC curves and Integral DSC curver for PE pipe: no impact, after exposure to formation water for 240 hours at 25 $\mathrm{MPa}$ and $40^{\circ} \mathrm{C}$, after exposure to $10 \%$ aqueous $\mathrm{HCl}$ solution at $50^{\circ} \mathrm{C}$ for 24 hours.

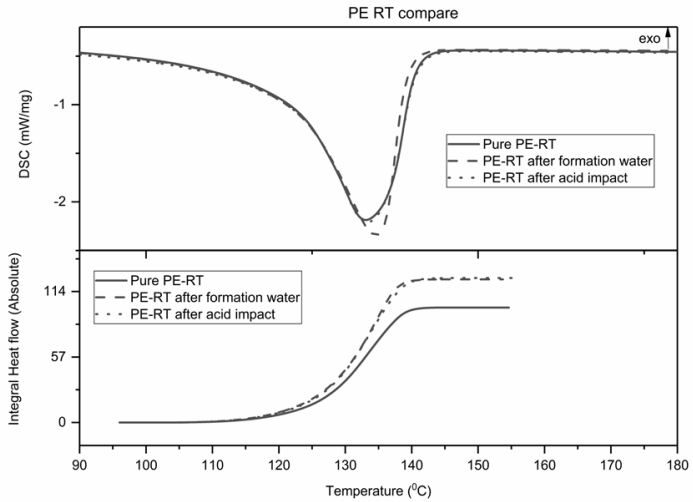

Fig. 6. DSC curves and Integral DSC curver for PE-RT pipe: no impact, after exposure to formation water for 240 hours at $25 \mathrm{MPa}$ and $40^{\circ} \mathrm{C}$, after exposure to $10 \%$ aqueous $\mathrm{HCl}$ solution at $50^{\circ} \mathrm{C}$ for 24 hours.

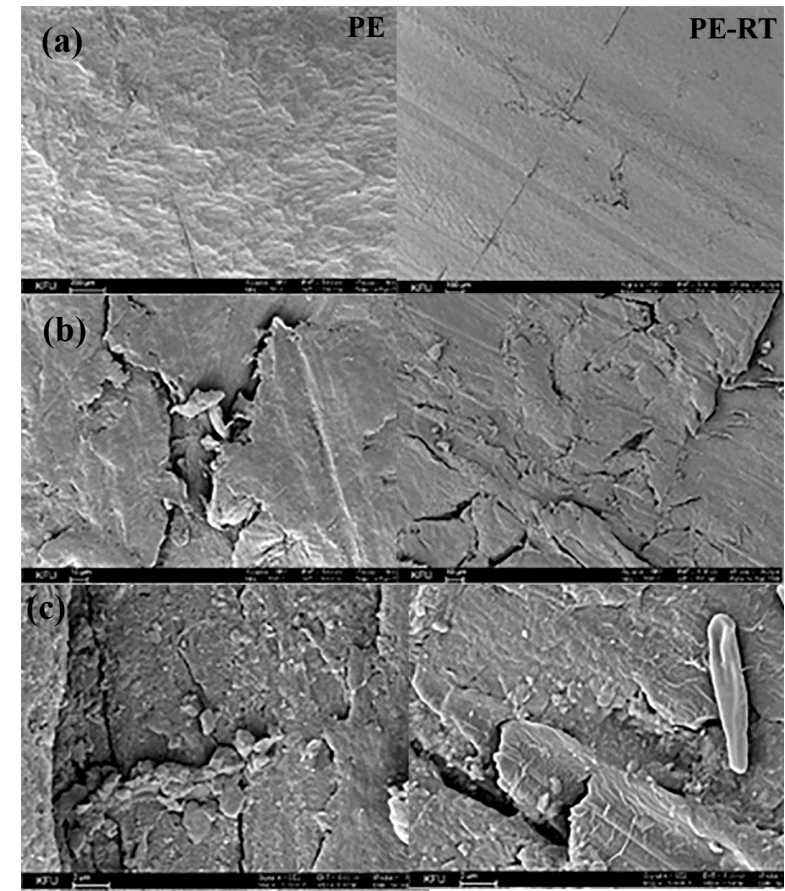

Fig. 7. Pictures of the surface of the polymer coating PE (left) and PE-RT (right) at different resolutions: a) resolution 200 and 100 microns; b) $10 \mu \mathrm{m}$ both polymers; c) 2 microns both polymers.

\section{Conclusions}

In this work the effect of formation water and hydrochloric acid on the samples of polymer coatings of high pressure pipes was studied. The exposure was made during 10 days at elevated temperature and pressure. Obtained mechanical properties of polymers after exposure changed sligthly no more than $11 \%$. Also, coefficient of thermal expansion did not changed dramatically. The DSC studies shows that thermal stability of polymeric materials stayed the same even in some cases became slighlty better after exposure. The formation water and hydrochloric acid did not affect the surface morphology of polymer coatings as well. All these results confirmed that studied polymeric materials 
can be used in high pressure pipes for transportation of aggresive media like formation water or hydrochloric acid and will protect the metal from corrosion.

\section{References:}

1 Al-Sherrawi M., Edaan E., Al-Rumaithi A., Sotnik, L, Lyashenko V., Features of Plastics in Modern Construction Use, International Journal of Civil Engineering and Technology, 9, pp. 975-984. (2018)

2 Lucas, E. F.; Mansur, C. R. E.; Spinelli, L.; Queirós, Y. G. C.; Pure Appl. Chem., 81, pp. 473 (2009)

3 Schramm D., PE-RT: A New Class of Polyethylene for Industrial Pipes. Proceedings of the International Conference on Offshore Mechanics and Arctic Engineering - OMAE. (2006)

4 R.E. Chapman, Chapter 8: The Nature of Petroleum Reservoirs, Developments in Petroleum Science, Elsevier, 16, pp 155-178, (1983) 